\title{
Physician mobility remains a "moving target"
}

$\mathrm{F}$ aced with a June 2010 deadline under the intergovernmental Agreement on Internal Trade, provincial medical regulatory colleges are struggling to find consensus on a new set of rules to govern the mobility of doctors in Canada.

Discussions among the colleges have been "a moving target," says Dr. Bryan Ward, president of the Federation of Medical Regulatory Authorities of Canada. "We're starting to see acceptance that we should all try to achieve a common standard, which is not what everybody believed a year ago."

Physicians with full Canadian qualifications who seek employment in another province have long been frustrated by the variety of hoops they must pass through to obtain a licence to practise in other jurisdictions.

Meanwhile, many of the international medical graduates recruited to rural and other hard-to-fill positions, who lack Canadian qualifications, have worked under conditions that block their mobility in this country. International graduates accounted for 53\% of new physicians starting practice in rural or remote areas in 2007, while they comprised only $22 \%$ of the national physician workforce, according to a recent Canadian Institute for Health Information study.

The trade agreement is a pact between federal, provincial and territorial governments to eliminate barriers to the free movement of people, goods and services. It challenges the status quo because it "removes from individual provincial regulators the ability to make an independent determination of the qualifications" of a physician who applies for a licence, says Dr. Rocco Gerace, registrar of the College of Physicians and Surgeons of Ontario.

Ward warns there are "two major downsides" if the federation cannot agree on common standards and unfettered mobility is actually permitted: an exodus of physicians, currently not mobile, from rural and difficult-to- recruit locations, and the movement of those doctors "into communities where there are no systems to monitor their practice as there might have been in the jurisdiction where they are registered."

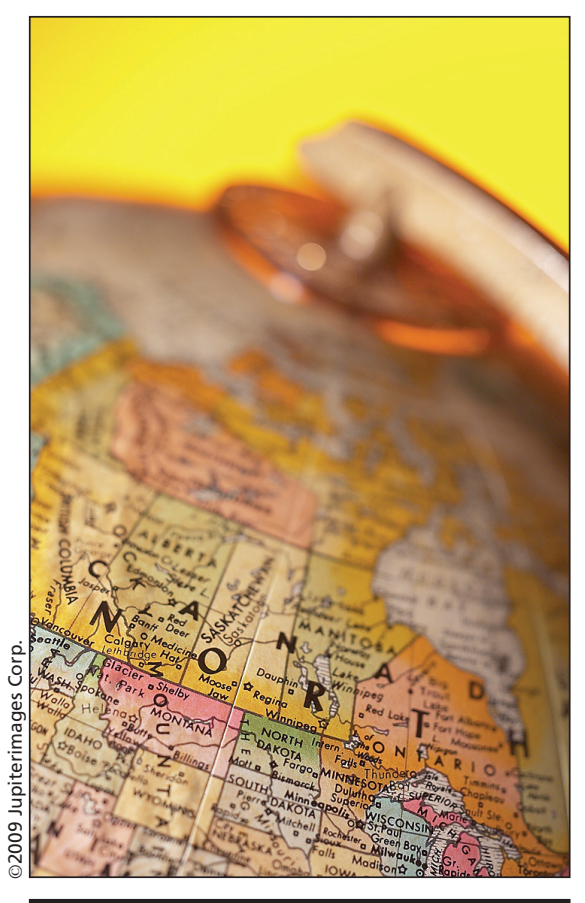

Some provinces have long argued that restricted licences are necessary for physician recruitment, particularly in attracting international medical graduates for practice in rural areas.

Proposals under consideration by the federation call for:

- a set of criteria for one national "gold standard" for full medical licensure for independent practice;

- an agreed-upon national set of restrictions and conditions on full licensure, and

- an agreed-upon national route for those licensed with restrictions and conditions to make the transition to a full licence.

As well, there is a proposal to give full mobility to all physicians currently licensed with full registration who lack the proposed "gold standard" qualifications but have practised for a continuous five years in Canada and successfully complete a "nationally acceptable comprehensive clinical assessment."

But whether the federation's 13 colleges will reach consensus on these proposals is an open question, as is the part to be played by provincial governments that may have their own agendas in terms of physician recruitment.

Provinces, many of which have "a role to play in accepting the registration criteria of the colleges of physicians," may also need to pass legislative and regulatory measures to facilitate change, Ward notes.

Dr. Karl Stobbe, president of the Society of Rural Physicians of Canada, is concerned that any agreement reached by the regulatory colleges will "fulfill the letter of the law" about free movement but the net effect will be to maintain the status quo.

Currently, standards for being granted a full medical licence differ among the provinces. Saskatchewan, for example, which has the highest proportion of international medical graduates (almost 50\%), does not require that doctors pass the Medical Council of Canada evaluation exams, though "it is time that Saskatchewan has this as a standard," says Dr. Dennis Kendel, registrar of the province's College of Physicians and Surgeons.

Regulators will need to "trust one another" that everyone grants full licences only to doctors who meet a common standard, says Ward. Under the proposed "gold standard" an applicant must:

- have a medical degree from an acceptable medical school listed in the World Directory of Medical Schools;

- be licensed by the Medical Council of Canada;

- have successfully completed a postgraduate medical program whose accreditation standards have been recognized by the College of Family Physicians of Canada or the Royal College of Physicians and Surgeons of Canada, and

- be certified by those colleges. 
Each province "has its own traditions and it is important that we are respectful of how far each has come" toward agreeing on a national standard, Ward says.

Some provinces have long argued that forms of restrictive licensing, with less rigid criteria, are necessary for physician recruitment, particularly in rural areas, and Kendel says it's realistic to acknowledge a continued call for "some forms of licences that are not full licensure."

But he adds it is "embarrassingly clear" that there are huge provincial variations in the terms under which special or restricted licences are granted to doctors who lack full qualifications.

Gerace says that if registrars could agree to standardize and limit the potential number of the restrictions, then "if that restriction is available in the receiving province, the doctor should be able to come." But no province would be obligated to accommodate a doctor with a restricted licence.

The proposal would also require that conditions or restrictions be placed directly on a doctor's licence to practise so "it will be transparent to everyone," says Ward, who is also deputy registrar of the Alberta College of Physicians and Surgeons. Currently, such restrictions are not necessarily attached to a physician's registration but may, for example, appear in terms of employment that stipulate monitoring and supervision, he says.

The push to come up with shared standards follows a 2007 decision by Canadian Premiers that the 1995 Agreement on Internal Trade will apply to regulated professions.

Amendments to the agreement's labour mobility chapter provide for an exception to full mobility only if the measure meets a "legitimate objective" (such as the protection of public health or safety), is not more restrictive than necessary to achieve that objective and doesn't create a "disguised restriction" to mobility.

The Federation of Medical Regulatory Authorities has to date been unsuccessful in its appeal for a one-year extension on compliance. - Ann Silversides, CMAJ

DOI:10.1503/cmaj.109-3050 